\title{
INCREASED RISK OF HORSE SENSITIZATION IN SOUTHWESTERN IRANIAN HORSE RIDERS
}

MOZHGAN MOGHTADERI ${ }^{1}$, SHIRIN FARJADIAN ${ }^{1,2}$, ZEYNAB HOSSEINI $^{3}$, and ALIREZA RAAYAT ${ }^{4}$

${ }^{1}$ Shiraz University of Medical Sciences, Shiraz, Iran

Allergy Research Center

${ }^{2}$ Shiraz University of Medical Sciences, Shiraz, Iran

Department of Immunology

${ }^{3}$ Shiraz University of Medical Sciences, Shiraz, Iran

Allergy Clinic of Ali-Asghar Hospital

${ }^{4}$ Shiraz University, Shiraz, Iran

Department of Clinical Sciences, School of Veterinary Medicine

\begin{abstract}
Objectives: The aim of this study has been to investigate the frequency of sensitization to horse allergens and clinical symptoms in horse riders. Material and Methods: A total of 42 horse riders and 50 healthy individuals were examined by means of skin prick tests for a panel of horse and common animal allergens, and pulmonary function tests were done by spirometry. Results: The rate of sensitization to horse allergens was $31 \%$ as proven by the skin prick test in horse riders whereas horse sensitization was not seen in the control group. Occupational allergy symptoms were reported by 19 horse riders. Two horse riders with no history of clinical symptoms showed positive skin reactions to horse allergens. Conclusions: To decrease the high risk of occupational sensitization among horse riders, workplace conditions should be improved to reduce the load of airborne horse allergens.
\end{abstract}

Key words:

Lung function, Skin prick test, Horse rider, Horse allergen, Animal allergy, IgE

\section{INTRODUCTION}

Most allergens are derived from plant or animal sources, and the animals that constitute the most frequent source of allergens in domestic or occupational settings are cats, dogs, cows, rats, mice, horses, rabbits and gerbils [1]. Horses generate large amounts of airborne allergens which can be found in horse dander, hair and skin scrapings [1,2]. Horse allergens are mainly acidic proteins, in which Equ c1 through c5 have been well characterized $[3,4]$.
Historical evidence shows that horses have been used as means of transportation for work, pleasure, and even as formidable weapons of war [5,6]. Currently, horses are widely used for recreational activities and competitive sports.

Horse allergy occurs in people who regularly work with horses, and horse riders experience long-term exposure which may lead to a variety of allergic diseases. Horse allergy is mainly characterized by rhinitis, conjunctivitis,

This work was supported by a grant from Shiraz University of Medical Sciences (grant No. 91-4707). Grant manager: Mozhgan Moghtaderi, MD.

Received: September 28, 2014. Accepted: January 8, 2015.

Corresponding author: S. Farjadian, Shiraz University of Medical Sciences, Department of Immunology, Allergy Research Center, Zand St., 71348-45794 Shiraz, Fars Province, Iran (e-mail: farjadsh@sums.ac.ir). 
asthma and urticaria; however, anaphylaxis has been reported in some cases $[6,7]$.

The induction of immunoglobulin $\mathrm{E}(\mathrm{IgE})$ formation after exposure to animal allergens is the main route of sensitization. The skin prick test (SPT) and determination of serum-specific IgE against horse allergens are helpful in the diagnosis of horse allergy. The SPT is safe, inexpensive, informative, and easy to perform. The concordance rate between the serum-specific IgE and SPT is reported to be around $90 \%$ [8].

Although equestrian culture has been very popular among Iranians since historical times, horse allergy has not been well studied among horse riders. This study has been designed to determine the incidence of horse sensitization in southwestern Iranian horse riders.

\section{MATERIAL AND METHODS}

Forty-two horse riders from the Fars Province in southwestern Iran were enrolled in this cross-sectional study. Participants with upper respiratory tract infections, cardiovascular diseases and those who received immunotherapy for inhalant allergens were excluded from the study.

Demographic information, job characteristics and smoking behavior of each participant were recorded by means of an interview. Clinical symptoms in the lungs, nose, skin and eyes after exposure to horses were recorded by means of a questionnaire. Fifty healthy individuals who had not worked with horses were selected as a control group of the same ethnicity and from the same geographic region. The study protocol was approved by our University Ethics Committee and each participant signed an informed consent form before being tested.

Skin prick tests were done for all participants with commercial allergens, including: epithelial allergens of a cat, cattle, dog, goat, gerbil, hamster, horse, rabbit, rat and mouse; bird feather allergens of a canary, chicken, duck, goose and parakeet, and allergen extracts of 2 species of mites, Dermatophagoides pteronyssinus and Dermatophagoides farina (GREER, USA). Histamine $(10 \mathrm{mg} / \mathrm{ml})$ and saline were used as positive and negative controls, respectively. The results of the skin tests were examined after $15 \mathrm{~min}$ and considered positive when the wheal was $\geq 3 \mathrm{~mm}$ greater in diameter than the negative control. The participants were asked to avoid any type of antihistamine medication for 5 days prior to the SPT.

Pulmonary function was evaluated by spirometry (Cosmed, Rome, Italy) for all participants. The forced vital capacity $(\mathrm{FVC})$, forced expiratory volume in $1 \mathrm{~s}\left(\mathrm{FEV}_{1}\right)$, ratio of forced expiratory volume in $1 \mathrm{~s}$ to forced vital capacity $\left(\mathrm{FEV}_{1} / \mathrm{FVC}\right)$ and peak expiratory flow $(\mathrm{PEF})$ were measured, and values below $80 \%$ of the predicted value were considered abnormal [9].

Statistical analysis was done by means of the $\mathrm{Chi}^{2}$ test using the version 6 of Epi Info. $P<0.05$ was considered statistically significant.

\section{RESULTS}

Forty-two horse riders (30 males, 12 females) in the age range of 12 to 48 years old participated in the study. The duration of horse riding was reported to be from 2 months to 35 years, and the related monthly exposure to horses varied from 3 days to 30 days per month. Fifty individuals ( 27 men, 23 women) in the age range of 17 to 54 years old were included in the control group. The Figure 1 shows the rate of positive reactions to 15 allergens in horse riders, as proven by the SPT and compared to the control group. In contrast to the absence of reactions to horse allergens in the control group, 13 horse riders ( $31 \%$ ) had positive skin reactions to the allergens.

The frequency of sensitization to mite allergens did not differ between horse riders and control participants $(16.7 \%$ vs. $18 \%, \mathrm{p}=0.8)$. Among 13 horse riders with positive reactions to horse allergens, 4 individuals also had positive reactions to mite allergens. 


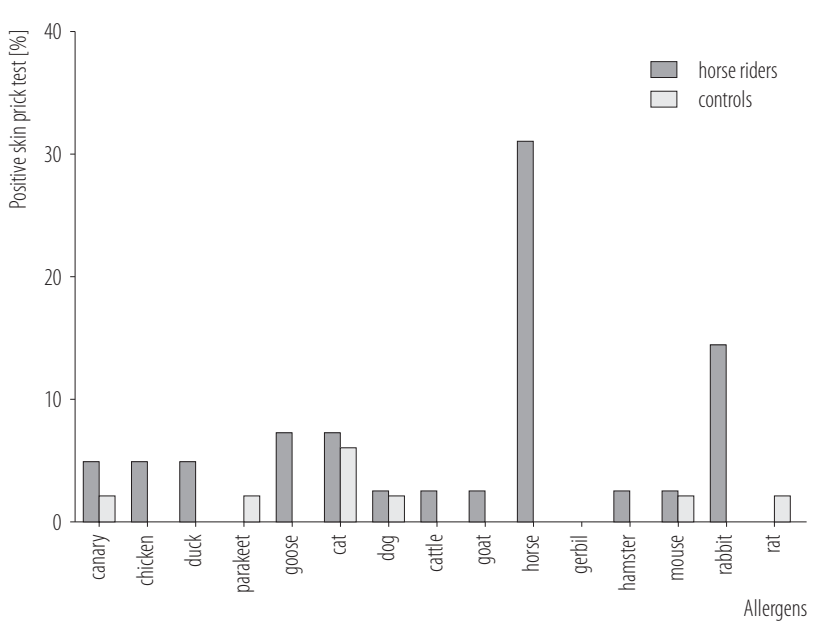

Fig. 1. Horse rider's sensitization to various animal allergens proven by the skin prick test as compared to the control group

Our results showed no correlation between the duration of horse exposure and increased sensitivity to horse allergens.

The questionnaire evaluation of clinical symptoms revealed occupational allergy symptoms in 19 horse riders, 11 of them being sensitized to horse allergens and 1 to mite allergens. The most common clinical symptoms included allergic rhinitis in 15 (35.7\%), conjunctivitis in 9 (21.4\%), asthma in $6(14.3 \%)$, and skin allergy in $5(11.9 \%)$ horse riders.

Two horse riders with no history of clinical symptoms showed positive skin reactions to horse allergens. None of horse riders who participated in the study were smokers.

The mean values of pulmonary function test parameters in horse riders compared to control group were $102.3 \pm 13.7 \%$ vs. $105.6 \pm 14.95 \%$ for the FVC, $101.8 \pm 15.9 \%$ vs. $113.4 \pm 16.2 \%$ for the $\mathrm{FEV}_{1}, 113.2 \pm 5.5$ vs. $110 \pm 12$ for the $\mathrm{FEV}_{1} / \mathrm{FVC}$ and $114.1 \pm 28.7 \%$ vs. $91.3 \pm 8.39 \%$ for the PEF. A peak expiratory flow $(\mathrm{PEF})<80 \%$ was observed in 1 horse rider whose skin test to horse allergens was also positive.

\section{DISCUSSION}

Occupational exposure to horses may cause sensitization and allergy among individuals who handle horses either professionally or for recreational purposes $[10,11]$. Horse riders are a specific group with high exposure to horses. The rate of sensitization to horse allergens was $31 \%$ according to the results of the SPT in our sample of horse riders. The prevalence of horse allergy varies from $1 \%$ to $10 \%$ depending on geography, climate, and the level of exposure [7,12,13]. Published data about horse allergy in specific target groups is limited; the study in Turkey reported the rate of sensitization to horse hair among grooms at $12.8 \%$ [14], and another study of veterinary medicine students from the Netherlands found the rate of sensitization to horse to be as low as $1.6 \%$ [15]. This variation may be explained by differences in the duration and intensity of the exposure to horse allergens, different epitopes of horse allergens, and genetic factors in people who work with horses.

Horse sensitization may occur by indirect exposure to horse allergens suspended in the air in the environment because of operations of ventilation systems in stalls or horse keepers [16]. We found no sensitization to horse allergens in our control group. The presence of equestrian clubs located far away from the city center may explain this finding.

In contrast to the control group, sensitization to rabbit allergens was detected in $6(14.3 \%)$ horse riders. Crossreaction between horse allergens and common mammalian allergenic epitopes, including a dog, cat, cow, guinea pig and rabbit, should be taken into consideration [17,18]. Mite sensitization did not differ significantly between our sample of horse riders and the control group. Since mites feed on human skin scales and animal dander [19], horse riders face the same risk of sensitization to these allergens as other people do.

The skin prick testing in combination with a detailed history should be sufficient for the diagnosis of horse allergy [20]. Despite the consistency between the results of the SPT and serum-specific IgE [8], our findings might have been strengthened by determining serum-specific $\mathrm{IgE}$ levels against different horse allergens. 
About $50 \%$ of the horse riders in this study had occupational allergy symptoms: 15 (79\%) had allergic rhinitis, 9 (47\%) - allergic conjunctivitis, 6 (31.5\%) - asthma, and $5(26.3 \%)$ - skin allergy. In the study in France, the prevalence of allergic symptoms among 56 individuals with allergy to horses was reported as ocular symptoms in the case of $64.3 \%$ of them, asthma in the case of $53.6 \%$ of them, and allergic rhinitis in the case of $42.8 \%$ of them [21]. In the study of allergies among a sample of grooms in Turkey, Tutluoglu et al. observed allergic rhinitis in the case of $42.2 \%$ of the studied grooms, allergic conjunctivitis in the case of $35.2 \%$ of them, asthma in the case of $14.4 \%$ of them, and allergic skin diseases in the case of $32.8 \%$ of them [14]. The results of these 2 studies were obtained from a self-administered questionnaire; because of the potential limitations in the accuracy of self-reported data, animal workers should be followed and physical examination performed by expert physicians is advisable. Nevertheless, a cross-sectional study by Ronmark et al. found that sensitization to horse allergens was a significant risk factor for the development of rhinitis and asthma [12]. In our study 2 horse riders with a positive skin test to horse allergens reported no history of clinical symptoms. False positive results may be induced by non-specific mast cell secretagogues or irritants in the allergen extracts or by infection with respiratory syncytial virus [20]. A positive skin test result is not enough to confirm the presence of allergic disease; however, it documents allergic sensitization which may predict the subsequent onset of allergic symptoms [20]. Based on our results, among 19 horse riders with clinical symptoms of horse allergy, only $11(58 \%)$ of them had a positive skin test to horse allergens. False negative skin tests might be caused by low potency of the prepared extract, weak puncture, concurrent parasitic infections and non-IgE-mediated mechanisms [20].

Except for 1 horse rider, all other riders in our sample had pulmonary function test results kept within permissible limits. Although the inhalation of small air-borne animal allergens may be considered a major cause of occupational asthma [22], horse riding is a type of cultural activity that often takes place in areas far away from cities, in settings characteristic of pure air and the absence of air pollution - the characteristics that may reduce the risk of pulmonary problems.

\section{CONCLUSIONS}

In conclusion, our findings reinforce the importance of allergen exposure in allergic sensitization. The frequency of horse sensitization among horse riders may be influenced by environmental factors, horse breeds, and individuals' genetic traits. Further research should consider horse sensitization among horse riders in other areas. Efforts to improve workplace air quality to reduce the load of airborne horse allergens are also potentially helpful.

\section{ACKNOWLEDGMENTS}

We thank K. Shashok (AuthorAID in the Eastern Mediterranean) for improving the use of English in the manuscript.

\section{REFERENCES}

1. Samadi S, Wouters IM, Heederik DJ. A review of bio-aerosol exposures and associated health effects in veterinary practice. Ann Agric Environ Med. 2013;20(2):206-21.

2. Felix K, Ferrándiz R, Einarsson R, Dreborg S. Allergens of horse dander: Comparison among breeds and individual animals by immunoblotting. J Allergy Clin Immunol. 1996;98(1):169-71, http://dx.doi.org/10.1016/S0091-6749 (96)70239-7.

3. Løowenstein H, Markussen B, Weeke B. Isolation and partial characterization of 3 major allergens of horse hair and dandruff. Int Arch Allergy Appl Immunol. 1976;51(1):48-67, http://dx.doi.org/10.1159/000231578.

4. Goubran Botros H, Poncet P, Rabillon J, Fontaine T, Laval JM, David B. Biochemical characterization and surfactant properties of horse allergens. Eur J Biochem. 2001;268(10): 3126-36, http://dx.doi.org/10.1046/j.1432-1327.2001.02217.x. 
5. McMiken DF. Ancient origin of horsemanship. Equine Vet J. 1990;22(2):73-8, http://dx.doi.org/10.1111/j.2042-33 06.1990.tb04214.x.

6. Gawlik R, Pitsch T, Dubuske L. Anaphylaxis as a manifestation of horse allergy. World Allergy Organ J. 2009;2(8): 185-9, http://dx.doi.org/10.1097/WOX.0b013e3181b2fe51.

7. Roberts G, Lack G. Horse allergy in children. BMJ. 2000;321(7256):286-7, http://dx.doi.org/10.1136/bmj.321.72 56.286 .

8. Leegaard J, Roth A. RAST in the diagnosis of hypersensitivity to horse allergens. A comparison with clinical history and in vivo tests. Clin Allergy. 1977;7:455-64, http://dx.doi. org/10.1111/j.1365-2222.1977.tb01476.x.

9. American Thoracic Society. Lung function testing: Selection of reference values and interpretative strategies. Am Rev Respir Dis. 1991;144(5):1202-18, http://dx.doi.org/10.1164/ ajrccm/144.5.1202.

10. Egmar AC, Almqvist C, Emenius G, Lilja G, Wickman M. Deposition of cat (Fel d 1), dog (Can f 1), and horse allergen over time in public environments - A model of dispersion. Allergy. 1998;53(10):957-61, http:/dx.doi.org/ 10.1111/j.1398-9995.1998.tb03796.x.

11. Arseneau AM, Hrabak TM, Waibel KH. Inhalant horse allergens and allergies: A review of the literature. Mil Med. 2012;177(7):877-82, http://dx.doi.org/10.7205/MIL MED-D-12-00038.

12. Rönmark E, Perzanowski M, Platts-Mills T, Lundbäck B. Different sensitization profile for asthma, rhinitis, and eczema among 7-8-year-old children: Report from the obstructive lung disease in Northern Sweden studies. Pediatr Allergy Immunol. 2003;14(2):91-9, http://dx.doi.org/10.1034/ j.1399-3038.2003.00042.x.

13. Novembre E, Mori F, Barni S, Pucci N, Rossi ME. Should the skin prick test to horse be included in the standard panel for the diagnosis of respiratory allergy? J Investig Allergol Clin Immunol. 2009;19:247-9.
14. Tutluoglu B, Atiş S, Anakkaya AN, Altug E, Tosun GA, Yaman M. Sensitization to horsehair, symptoms and lung function in grooms. Clin Exp Allergy. 2002;32(8):1170-3, http:// dx.doi.org/10.1046/j.1365-2745.2002.01439.x.

15. Samadi S, Spithoven J, Jamshidifard AR, Berends BR, Lipman L, Heederik DJ, et al. Allergy among veterinary medicine students in The Netherlands. Occup Environ Med. 2012;69(1):48-55, http://dx.doi.org/10.1136/oem.2010. 064089 .

16. Liccardi G, Emenius G, Merritt AS, Salzillo A, D’Amato M, D'Amato G. Direct and indirect exposure to horse: Risk for sensitization and asthma. Curr Allergy Asthma Rep. 2012;12(5):429-37, http://dx.doi.org/10.1007/s11882012-0280-5.

17. Liccardi G, Salzillo A, Piccolo A, D’Amato G. Skin prick test to horse should be included in the standard panel for the diagnosis of respiratory allergy. J Investig Allergol Clin Immunol. 2010;20(1):93-4.

18. Baker J, Berry A, Boscato LM, Gordon S, Walsh BJ, Stuart MC. Identification of some rabbit allergens as lipocalins. Clin Exp Allergy. 2001;31(2):303-12, http://dx.doi. org/10.1046/j.1365-2222.2001.00973.x.

19. Spieksma FT. Cultures of house-dust mites on animal skin scales. Allergol Immunopathol (Madr). 1976;4(6):419-28.

20. Demoly P, Bousquet J, Romano A. In vivo methods for the study of allergy. In: Adkinson NF, Bochner BS, Busse WW, Stephen T, editors. Middleton's allergy principles and practice. Philadelphia: Mosby Elsevier; 2009. p. 1275-7.

21. Lelong M, Castelain MC, Bras C, Drain JP, Léonard JC, Robberecht MN, et al. [An outbreak of allergy to horses in children. A review of 56 recent cases]. Pediatrie. 1992;47(1): 55-8. French.

22. Gallagher LM, Crane J, Fitzharris P, Bates MN. Occupational respiratory health of New Zealand horse trainers. Int Arch Occup Environ Health. 2007;80(4):335-41, http:// dx.doi.org/10.1007/s00420-006-0141-4.

This work is available in Open Access model and licensed under a Creative Commons Attribution-NonCommercial 3.0 Poland License - http://creativecommons.org/ licenses/by-nc/3.0/pl/deed.en. 